\title{
A Study on Physical and Physiological Impact of Polycystic Ovary Syndrome
}

\author{
Mr. Sathish Kumar B.P ${ }^{1}$, Dr. Lipika Das ${ }^{* 2}$, Dr. Sayantan Ghosh ${ }^{3}$, Dr. Aksa Merin Jose ${ }^{4}$ \\ 1. Associate Professor, Department of Pharmacy Practice, Sri Adichunchanagiri College of Pharmacy, Mandya, Karnataka, India. \\ 2. Pharm D Intern, Department of Pharmacy Practice, Sri Adichunchanagiri College of Pharmacy, Mandya, Karnataka, India. \\ *Corresponding author's E-mail: drlipikadas24@hotmail.com
}

Received: 05-06-2021; Revised: 22-07-2021; Accepted: 30-07-2021; Published on: 15-08-2021. ABSTRACT

Polycystic ovary syndrome is a relatively common hormonal disorder that causes a number of different symptoms in women of reproductive age. In such conditions, enlarged ovaries containing multiple small cysts (polycystic ovaries), are found. Although most women with PCOS have polycystic ovaries, some affected women do not. Common to all women with PCOS is an irregularity in menstrual cycle and the presence of excess male hormones (androgen). It disrupts the functioning of the reproductive organs that produce progesterone and estrogen, the hormones that regulate the menstrual cycle. A prospective observational study was carried out in 125 inpatients, after taking written informed consent from patients those who met the study criteria. A total of 125 patients were enrolled in the study, it was observed that $17.74 \%$ have experienced moderate depression, $18.54 \%$ patients experienced major irregular menstrual period problem, $2-25 \%$ of the patients were dealing with body weight, and $6.45 \%$ patients were identified that the growth of visible hair on the upper lip as a major problem. It was also found that $8.87 \%$ of patients experienced major menstrual cramps and patients were found worried about PCOS and hence disturbing their quality of life. Various long-term complication and co morbidities have been associated with PCOS and early diagnosed and therapeutic interventions are needed. PCOS is a chronic disease with manifestations across the life span and represents a major health and economic burden. Management should focus on support, education, addressing physiological factors and strongly emphasizing healthy lifestyle with targeted medical therapy as required. Addressing hyperandrogenism is clinically important and monitoring for and managing longer-term metabolic complications including dyslipidemia, IGT, DM2, cardiovascular risk factors, is crucial. Overall, further research is needed in this complex condition.

Keywords: Polycystic ovary syndrome (PCOS), physical impact, Physiological impact, Hyperandrogenism, Gynecology, and obstetrics.

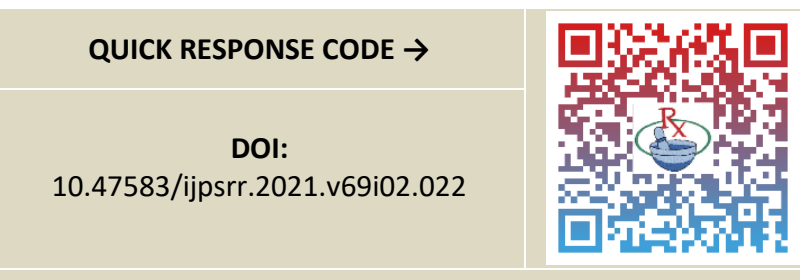

DOI link: http://dx.doi.org/10.47583/ijpsrr.2021.v69i02.022

\section{INTRODUCTION}

$\mathrm{P}$ olycystic ovary syndrome (PCOS) is a very complex and yet common endocrine disorder in women in reproductive age group. ${ }^{1}$ It is a hyperandrogenic disorder which is closely accompanied by chronic oligoanovulation. ${ }^{2}$ Often polycystic ovary syndrome has psychological impacts (depression and mood disorders) and metabolic disorders, primarily insulin resistance (hyperinsulinemia), which is also responsible for altered metabolism and production of androgen. ${ }^{3}$ Almost $5-10 \%$ of reproductive-aged women is affected by this endocrinemetabolic disorder (characterized by multiple hormonal imbalances), imitating on a clinical presentations subjugated by signs of hyperandrogenism, eventually generating a short and long term consequences on the female health. ${ }^{4,5}$ Women with PCOS denotes an interesting biological model explaining the relation between cardiovascular risk profile and hormonal pattern. Certainly, even at an early age these women shows symptoms of cardiovascular disorders ${ }^{6}$, like hypertension, obesity, insulin resistance, reduced cardiopulmonary functional capacity, chronic inflammation and autonomic dysfunctions. $^{7}$

In spite of a wide range of researches, the etiology of PCOS still remains unknown, even though the genetic and environmental factors are connected. ${ }^{8}$ Current evidences put forward the suggestions that the key role in etiology is played by the ovarian theca cells, which is the major source of androgen secretion and production. Also the syndrome might be caused by the hypothalamicpituitary axis and impaired insulin activity. ${ }^{9,10}$ Moreover, the altered activity in sympathetic nervous system has also been proposed in the etiology. ${ }^{11}$

Even in the early twenties, women diagnosed with PCOS, exhibit a wide range of metabolic and cardiovascular disorders. The predominant feature is obesity in women with PCOS (more than $50 \%$ of women diagnosed with PCOS in overweight). Furthermore, Women with PCOS are most likely to have wide waist and increase in visceral obesity. In comparison with peripheral fat, central fat is connected to insulin resistance (fatty acids are recycled more rapidly through lipolysis. Basically, obesity in women with PCOS in associated with increase in insulin resistance dyslipidemia and glucose intolerance. ${ }^{12}$

There is a broad band of therapeutic options and a wide range of lifestyle intervention and also specific 
pharmacological agents available. Pharmacological agents are effective but come with a list of adverse effects. PCOS is a life-long illness and these patients needs a long lasting treatment option as there is a increase risk of associated illness. ${ }^{13}$

Eventually, PCOS has a significantly negative effect on patient's health related quality of life (HRQoL). ${ }^{14} \mathrm{It}$ is found that women with PCOS have a increased rate of depression as compared to other women. ${ }^{15}$ Similarly, they also report a higher rate of anxiety compared to healthy women. ${ }^{16}$ Adolescent girls with PCOS have also reported with high anxiety levels. In compared to women with other chronic conditions (like back pain, diabetes and arthritis), Women suffering from PCOS has shown alike or improved HRQoL, but a poor psychological HRQol. ${ }^{17}$ A well developed and established questionnaire has been developed for women with PCOS, to evaluate the HRQoL in relation to PCOS. ${ }^{18}$

\section{METHODS}

\section{Study site:}

The study was conducted in Adhichunchanagiri Hospital and Research Center.

\section{Study design:}

This study was a "Prospective Observational study".

\section{Study period:}

The study was conducted for a period of 6 months from October 2019 to April 2020.

\section{Study criteria:}

\section{Inclusion criteria:}

All patients attending outpatient clinics or on admission in the ward within the period of study were included in the study after consent.

\section{Exclusion criteria:}

Patient who are not willing to participate are excluded from the study.

\section{RESULTS}

A total of 125 patients were enrolled in the study and these were reviewed over a period of 6 months from October 2019 to April 2020. The patient data was collected through a Case collection form and Standardized Questionnaire.

- $\quad$ GGE-

From Table 01 Statistical allowance shows that the average age of the patient was 25.22 years with a standard deviation of \pm 3.3864 as shown in Table 01 .

\section{- BMI-}

From Table 01 Statistical Analysis shows that the average BMI was found to be 25.6055 with a standard deviation of \pm 3.60 as shown in Table 01 .
- AOM-

From Table 01 Statistical Analysis shows that the average AOM was found to be 14.06452 with a standard deviation of \pm 1.721505 as shown in Table 01 .

- $\mathrm{FSH}-$

From Table 01 Statistical Analysis shows that the average FSH was found to be 4.791129 with a standard deviation of \pm 3.843939 as shown in Table 01 .

- LH-

From Table 02 Statistical Analysis shows that the average LH was found to be 4.298374 with a standard deviation of \pm 1.846878 as shown in Table 01 .

- FBS-

From Table 01 Statistical Analysis shows that the average FBS levels was found to be 100.9516 with a standard deviation of \pm 10.77247 as shown in Table 01 .

- Ferriman Galaway Score-

From Table 01 Statistical Analysis shows that the average ferriman-galaway score was found to be 7.74193 with a standard deviation of \pm 2.738 as shown in Table 01 .

- Infertility Duration-

From Table 01 Statistical Analysis shows that the average infertility duration was found to be 3.08 with a standard deviation of \pm 2 .6as shown in Table 01 .

- S Prolactin-

From Table 01 Statistical Analysis shows that the average S Prolactin levels was found to be 169 with a standard deviation of \pm 63.9 as shown in Table 01 .

Patient Distribution-

Table 01: Statistical Analysis of Patients

\begin{tabular}{|l|l|l|}
\hline Patients (125) & Mean & $\begin{array}{l}\text { Standard } \\
\text { Deviation } \pm\end{array}$ \\
\hline AGE & 25.22581 & 3.383639 \\
\hline BMI & 25.60548 & 3.607733 \\
\hline AOM & 14.06452 & 1.721505 \\
\hline FSH & 4.791129 & 3.843939 \\
\hline LH & 4.298374 & 1.846878 \\
\hline FBS & 100.9516 & 10.77247 \\
\hline Ferriman Gallaway & 7.741935484 & 2.738232794 \\
\hline Score & & \\
\hline Infertility Duration & 3.080645161 & 2.616932377 \\
\hline S. Prolactin & 169 & 63.98638968 \\
\hline
\end{tabular}


Polycystic Ovary Syndrome- Quality of Life Questionnaire (Cronin et al; 1998)

The PCOSQL questionnaire consists of 26 questions, which represents 5 domains (question numbers):

- $\quad$ Emotions $(2,4,6,11,14,17,18)$

- $\quad$ Body hair $(1,9,15,16,26)$

- Weight $(3,10,12,22,24)$
- Infertility $(5,13,23,25)$

- Menstrual problems $(7,8,19,20,21)$

Each question is associated with a 7-point scale in which 7 represents optimal function and 1 represents the poorest function. The results are represented on 1 to 7 scales by dividing each domain score by the number of items in the domain. The results from a domain with 4 items and from the domain with 7 items will be both expressed as a score from 1 to 7 .

Table 02: Statistical distribution of patients according to the domains

\begin{tabular}{|l|c|c|c|c|}
\hline Domain & No. of Patients & Mean & Median & Standard Deviation \pm \\
\hline Emotion & 125 & 4.774194 & 4.714286 & 0.433572 \\
\hline Body hair & 125 & 4.753226 & 4.8 & 0.637591 \\
\hline Weight & 125 & 4.787097 & 4.8 & 0.551094 \\
\hline Infertility & 125 & 4.6875 & 4.75 & 0.570287 \\
\hline Menstrual problems & 125 & 4.430645 & 4.6 & 0.651571 \\
\hline
\end{tabular}

Table 03: Representation of each question with 7-point scale

\begin{tabular}{|l|l|c|c|c|}
\hline Question number & Question & Score & Frequency & Percentage \\
\hline 2 & Depressed as a result of having PCOS & 5 & 49 & 39.5 \\
\hline 5 & Concerned with infertility problems & 4 & 35 & 28.2 \\
\hline 8 & Irregular menstrual periods & 5 & 30 & 24.1 \\
\hline 9 & Growth of visible hair on upper lip? & 5 & 44 & 35.4 \\
\hline 15 & Growth of visible hair on your face? & 5 & 40 & 32.5 \\
\hline 14 & Felt frightened of getting cancer? & 5 & 52 & 41.9 \\
\hline 20 & Late menstrual period? & 4 & 31 & 25 \\
\hline 21 & Menstrual cramps? & 5 & 37 & 29.8 \\
\hline
\end{tabular}

Figure 01: Graphical representation of each question with 7-point scale

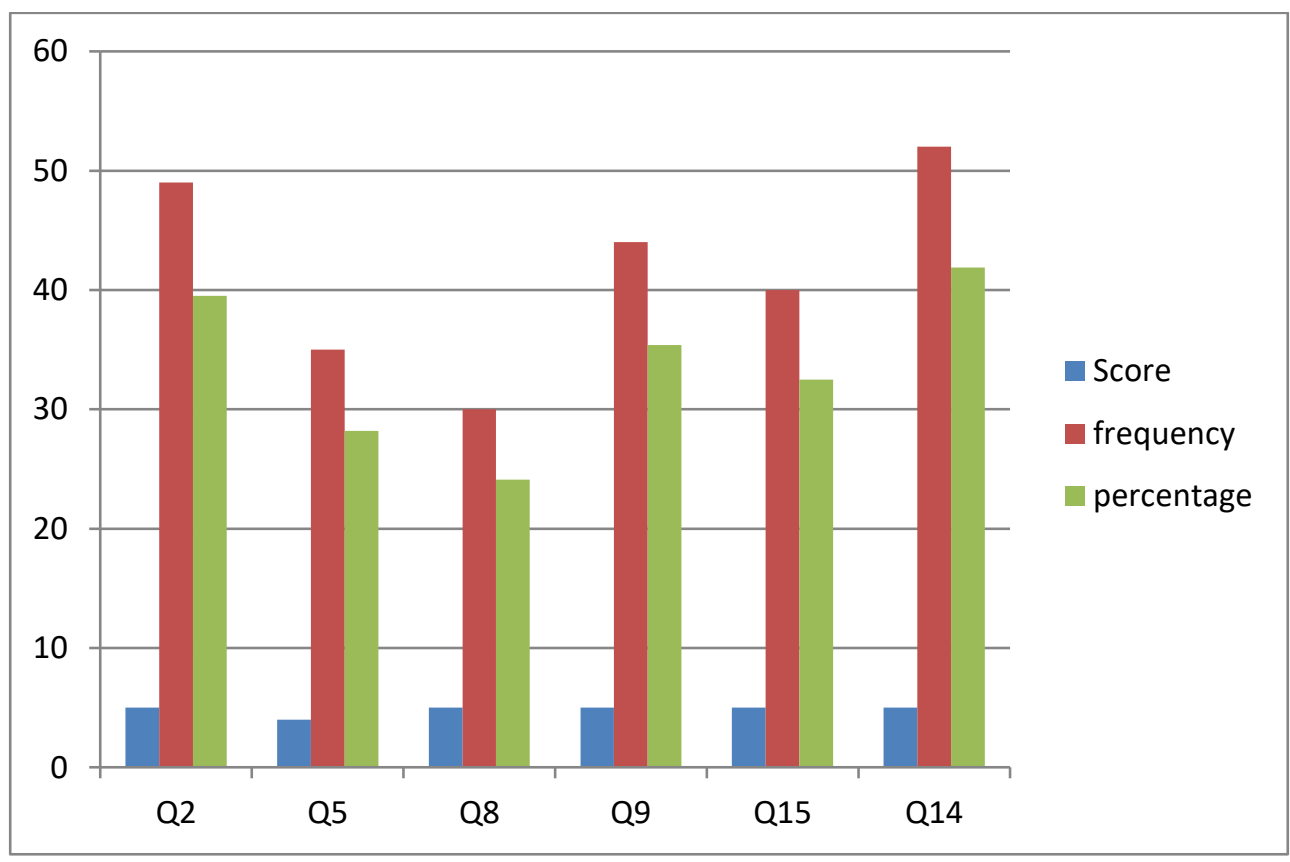




\section{DISCUSSION}

The objective of this study was to assess the physical and physiological changes in PCOS patients and to assess the quality of life.

A total of 125 patients participated in the study.

In this study it was observed that women with PCOS tend to experience mild to moderate depression, which concur with the findings of present study. It was observed that $17.74 \%$ have experienced moderate depression and $39.51 \%$ of women have experienced mild depression. Similar findings were reported by S Tan, et al in which $23.9 \%$ of patients had scores indicating mild to moderate depression. ${ }^{19}$ Another study was conducted by Xican Yin, et al, women with PCOS reported significantly higher depression, anxiety and lower QoL. ${ }^{20}$

In our study $18.54 \%$ patients experienced major problem and $15.32 \%$ of patients experienced moderate problems of irregular menstrual periods. This study is compared with the study conducted by Vasiliki Christodoulopoulou, et al in which the number of patients were more in contrast to this study, in which a total of $72.2 \%$ women suffered from menstrual cycle disorder in PCOS. ${ }^{21}$ Another study conducted by Syeda Sidra, et al in which patients exhibited the cardinal symptoms of PCOS, including irregular menstruation $(n=316,71 \%){ }^{22}$

\section{CONCLUSION}

This study has provided baseline data regarding the Health related Impacts of PCOS. The findings from this thesis have a number of implications for clinical practice. One of the most important is for health care professionals to be aware that women with PCOS are likely to experience depression and anxiety and be prepared to offer appropriate support to these women. Moreover, this thesis revealed that women with PCOS might be unable to meet child related goals. PCOS can be a changing condition, which makes it difficult for women with PCOS to manage their symptoms over time. As such, health care professionals should be considerate that symptoms of PCOS, and the necessary treatments, will change over the lifespan. Women with PCOS should therefore be required to follow up with their health care professional on a regular basis in order to help them maintain control over their condition, or indeed, to change treatments when necessary.

\section{ACKNOWLEDGEMENT:}

The authors of the study are heartly thankful for the guidance and support received from all the members who contributed to this project, it was vital for the success of the project. They would also like to express their sincere thanks to all the study participants.

\section{Author Contributions:}

Author's role in study concept and design, acquisition of subjects and/or data, analysis and interpretation of data, and preparation of manuscript
Study Concept: Mr. Sathish Kumar B.P, Dr. Lipika Das, Dr. Sayantan Ghosh

Acquisition of subjects and/or data: Dr. Aksa Merin Jose, Dr. Lipika Das

Interpretation of Data: Mr. Sathish Kumar B.P, Dr. Lipika Das, Dr. Sayantan Ghosh

Preparation of Manuscript: Dr. Lipika Das, Dr. Aksa Merin Jose

\section{Declaration of Conflicting Interests}

The author(s) declared no potential conflicts of interest with respect to the research, authorship, and/or publication of this article.

Source of funding: The author(s) received no financial support for the research, authorship, or publication of this article.

\section{Available data and materials:}

All the information related to the study is embedded within the manuscript.

\section{REFERENCES}

1. Weiss TR, Bulmer SM. Young women's experiences living with polycystic ovary syndrome. Journal of obstetric, gynecologic \& neonatal nursing. 2011 Nov 1;40(6):709-18.

2. ESHRE TR, ASRM-Sponsored PCOS Consensus Workshop Group. Revised 2003 consensus on diagnostic criteria and long-term health risks related to polycystic ovary syndrome. Fertility and sterility. 2004 Jan 1;81(1):19-25.

3. Escobar-Morreale HF, Botella-Carretero JI, AlvarezBlasco F, Sancho J, San Millán JL. The polycystic ovary syndrome associated with morbid obesity may resolve after weight loss induced by bariatric surgery. The Journal of Clinical Endocrinology \& Metabolism. 2005 Dec 1;90(12):6364-9.

4. Rojas J, Chávez M, Olivar L, Rojas M, Morillo J, Mejías J, Calvo M, Bermúdez V. Polycystic ovary syndrome, insulin resistance, and obesity: navigating the pathophysiologic labyrinth. International journal of reproductive medicine. 2014 Oct;2014.

5. Hashemi S, Tehrani FR, Farahmand M, Khomami MB. Association of PCOS and its clinical signs with sexual function among Iranian women affected by PCOS. The journal of sexual medicine. 2014 Oct 1;11(10):2508-14.

6. Orio Jr F, Giallauria F, Palomba S, Cascella T, Manguso F, Vuolo L, Russo T, Tolino A, Lombardi G, Colao A, Vigorito C. Cardiopulmonary impairment in young women with polycystic ovary syndrome. The Journal of Clinical Endocrinology \& Metabolism. 2006 Aug 1;91(8):2967-71.

7. Apridonidze T, Essah PA, luorno MJ, Nestler JE. Prevalence and characteristics of the metabolic 
syndrome in women with polycystic ovary syndrome. The Journal of Clinical Endocrinology \& Metabolism. 2005 Apr 1;90(4):1929-35.

8. Franks $S$, Webber $\amalg$, Goh M, Valentine A, White DM, Conway GS, Wiltshire S, McCarthy MI. Ovarian morphology is a marker of heritable biochemical traits in sisters with polycystic ovaries. The Journal of Clinical Endocrinology \& Metabolism. 2008 Sep 1;93(9):3396402.

9. Gilling-Smith C, Story H, Rogers V, Franks S. Evidence for a primary abnormality of thecal cell steroidogenesis in the polycystic ovary syndrome. Clinical endocrinology. $1997 \mathrm{Jul} ; 47(1): 93-9$.

10. Rebar RH, Judd HL, Yen SS, Rakoff J, Vandenberg G, Naftolin F. Characterization of the inappropriate gonadotropin secretion in polycystic ovary syndrome. The Journal of clinical investigation. 1976 May 1;57(5):1320-9.

11. Greiner M, Paredes A, Araya V, Lara HE. Role of stress and sympathetic innervation in the development of polycystic ovary syndrome. Endocrine. 2005 Dec;28(3):319-24.

12. Bargiota A, Diamanti-Kandarakis E. The effects of old, new and emerging medicines on metabolic aberrations in PCOS. Therapeutic advances in endocrinology and metabolism. 2012 Feb;3(1):27-47.

13. Stener-Victorin E, Jedel E, Janson PO, Sverrisdottir YB. Low-frequency electroacupuncture and physical exercise decrease high muscle sympathetic nerve activity in polycystic ovary syndrome. American Journal of Physiology-Regulatory, Integrative and Comparative Physiology. 2009 Aug 1.

14. Deeks AA, Gibson-Helm ME, Paul E, Teede HJ. Is having polycystic ovary syndrome a predictor of poor psychological function including anxiety and depression?. Human Reproduction. 2011 Jun 1;26(6):1399-407.

15. Bazarganipour F, Ziaei S, Montazeri A, Foroozanfard F, Kazemnejad A, Faghihzadeh S. Psychological investigation in patients with polycystic ovary syndrome. Health and quality of life outcomes. 2013 Dec;11(1):1-8.

16. Laggari $\mathrm{V}$, Diareme $\mathrm{S}$, Christogiorgos $\mathrm{S}$, Deligeoroglou $\mathrm{E}$, Christopoulos P, Tsiantis J, Creatsas G. Anxiety and depression in adolescents with polycystic ovary syndrome and Mayer-Rokitansky-Küster-Hauser syndrome. Journal of Psychosomatic Obstetrics \& Gynecology. 2009 Jan 1;30(2):83-8.

17. Coffey S, Bano G, Mason HD. Health-related quality of life in women with polycystic ovary syndrome: a comparison with the general population using the Polycystic Ovary Syndrome Questionnaire (PCOSQ) and the Short Form-36 (SF-36). Gynecological Endocrinology. 2006 Jan 1;22(2):80-6.

18. Eggers S, Kirchengast $S$. The polycystic ovary syndrome-a medical condition but also an important psychosocial problem. Collegium antropologicum. 2001 Dec 17;25(2):673-85.

19. Benson S, Janssen OE, Hahn S, Tan S, Dietz T, Mann K, Pleger K, Schedlowski M, Arck PC, Elsenbruch S. Obesity, depression, and chronic low-grade inflammation in women with polycystic ovary syndrome. Brain, behaviour, and immunity. 2008 Feb $1 ; 22(2): 177-84$.

20. Yin $\mathrm{X}$, Ji $\mathrm{Y}$, Chan $\mathrm{CL}$, Chan $\mathrm{CH}$. The mental health of women with polycystic ovary syndrome: a systematic review and meta-analysis. Archives of Women's Mental Health. 2020 Jun 9:1-7.

21. Christodoulou V, Trakakis E, Pergialiotis B, Peppa M, Chrelias C, Kassanos D, Papantiniou N. Clinical and biochemical characteristics in pcos women menstrual abnormalities. J Family Reprod Health. 2016 Dec; 10(4):184-190.

22. Sidra S, Tariq MH, Farrukh MJ, Mohsin M. Evaluation of clinical manifestations, health risks, and quality of life among women with polycystic ovary syndrome. PloS one. 2019 Oct 11;14(10):e0223329.

Source of Support: The author(s) received no financial support for the research, authorship, and/or publication of this article.

Conflict of Interest: The author(s) declared no potential conflicts of interest with respect to the research, authorship, and/or publication of this article.

For any question relates to this article, please reach us at: editor@globalresearchonline.net New manuscripts for publication can be submitted at: submit@globalresearchonline.net and submit_ijpsrr@rediffmail.com 